\title{
Problems with ABPI proposals to release data on payments to doctors
}

\author{
Ben Goldacre research fellow \\ London School of Hygiene and Tropical Medicine, London WC1E 7HT, UK
}

Whitehead of the Association of the British Pharmaceutical Industry (ABPI) says the drug industry will soon declare all payments to doctors. ${ }^{12}$ There are several problems with his new promises.

Firstly, industry has been promising such transparency for years, without delivering. At the same time, the same companies are campaigning against transparency in other areas.

Secondly, industry representatives now say-when directly questioned about completeness - that EU privacy law will permit individual doctors to opt out of having their payments declared. Some of the most important data will still be hidden.

Thirdly, doctors' potential conflicts of interest extend beyond payments from drug companies to include payments from PR firms, income from local healthcare providers, and more.

This is why we suggest that doctors should be obliged to declare their own complete list of competing interests, ideally to the General Medical Council. ${ }^{1}$

Greater transparency from the ABPI is still welcome. The limited, incomplete dataset it provides could be merged with other data sources to provide a more complete picture and help identify gaps that may signal areas and individuals of greater concern.

Unfortunately the ABPI currently plans to release this information through its own website. It says it wants to provide a "one stop" service with web pages for patients wishing to find out about their doctors. In reality, this will mean that a flawed and incomplete dataset is presented to the public, as if complete, under editorial control of industry, with better uses unnecessarily obstructed.

The ABPI could release this information as structured open data, in open formats, freely available for reuse by third parties, as is now standard practice in government and other sectors. ${ }^{3}$ Its data could then be aggregated and matched against other sources to produce genuinely useful information and insights. The ABPI should reconsider.

Competing interests: I am a co-signatory to the initial letter calling for the GMC to run a competing interests database. I am a collaborator on a website allowing doctors to declare their own competing interests. I receive income from speaking and writing for lay audiences on problems in medicine, including competing interests.

Full response at: www.bmj.com/content/348/bmj.g236/rr/682926.

1 Whitehead S. ABPI efforts to increase transparency about competing interests. BMJ 2014;348:g1300.

2 McCartney M, Goldacre B, Chalmers I, Reynolds C, Mendel J, Smith S, et al. Why the GMC should set up a central registry of doctors' competing interests. BMJ 2014:348:g236 (15 January.).

3 Cabinet Office. Open Data: unleashing the potential. 2012. www.gov.uk/government/ publications/open-data-white-paper-unleashing-the-potential.

Cite this as: BMJ 2014;348:g1301

๑ BMJ Publishing Group Ltd 2014 